\title{
ReaR
}

\section{hernia vesical en unidad de cuidados intensivos, diagnostico infrecuente. informe de un caso y revisión de la literatura.}

Sosa Remón A. Jerez Álvarez AE, Chávez Remón CE, González Muñoz D.

Hospital clínico-quirúrgico "Celia Sánchez Manduley". Manzanillo, Granma, Cuba.

\section{Resumen}

La hernia vesical se define como una porción de la vejiga urinaria o divertículo que sale a través del orificio de una hernia. Es una entidad rara presente en tan solo el 1 al $3 \%$ de las hernias inguinoescrotales. Su diagnóstico se basa en la alta sospecha clínica y la realización de una prueba de imagen. Se presenta el caso de un paciente masculino de 43 años, con hernia vesical, la cual se manifestó como una masa inguinoescrotal izquierda, relacionada a sintomatología urinaria obs-tructiva, con necesidad de ejercer presión sobre el testículo homolateral para ejecutar la micción. Fue diagnosticado por uretrocistografía re-trógrada y ultrasonido. En las placas antero-posterior y oblicua se evidenció hernia vesical, aproximadamente del $40 \%$ por el conducto inguinal izquierda. En la placa post-miccional, ésta disminuyó su tamaño, pero sin va-ciamiento completo.

\section{Introducción}

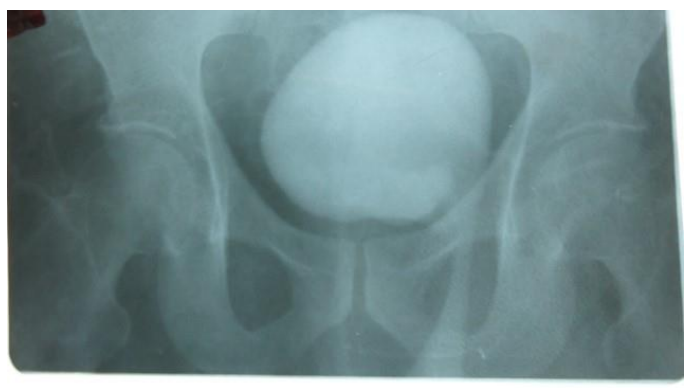

La hernia vesical se define como una porción de la vejiga urinaria $o$ divertículo que sale a través del orificio de una hernia. Es una entidad rara presente en tan solo el 1 al $3 \%$ de las hernias inguinoescrotales.

$\mathrm{Su}$ diagnóstico se basa en la alta sospecha clínica y la realización de una prueba de imagen. Se presenta el caso de un paciente masculino de 43 años, con hernia vesical, la cual se manifestó como una masa inguinoescrotal izquierda, relacionada a sintomatología urinaria obstructiva, con necesidad de ejercer presión sobre el testículo homolateral para ejecutar la micción. Fue diagnosticado por uretrocistografía retrógrada y ultrasonido. En las placas antero-posterior y oblicua se evidenció hernia vesical, aproximadamente del 40 $\%$ por el conducto inguinal izquierda. En la placa post-miccional, ésta disminuyó su tamaño, pero sin vaciamiento completo.

\section{Presentación del Caso}

Varón de 43 años de edad, con antecedentes de etilismo habitual y tabaquismo ocasional, obeso e hipertenso con mal cumplimiento del tratamiento de base.

Ingresó a la Unidad de Cuidados Intensivos (UCI) bajo el problema diagnóstico de un cuadro de disfunción aguda del ventrículo izquierdo secundario a una emergencia hipertensiva. 
Al completar su historial clínico, el paciente refirió un cuadro de alrededor de un año de evolución, caracterizado por la presencia de disminución del calibre miccional, además de polaquiuria de hasta 8 micciones por día, con necesidad de ejercer compresión escrotal para completar la misma, asociado a un defecto herniario inguinal ipsilateral. A la exploración física destacaba la presencia de hernia inguinal izquierda, indirecta, reductible, sin compromiso vascular.

El ultrasonido realizado con transductor de partes blandas (sonda lineal de 8 Mhz) evidenció imagen ecolúcida en proyección de bolsa escrotal izquierda sin peristaltismo visible. En rastreo ecográfico vesical con transductor de 3,75 Mhz, en su región izquierda, delimitó la presencia del defecto en la continuidad mural.

Se realizó cistografía retrógrada, observándose en placas de llenado la presencia de hernia vesical por defecto de región inguinal derecha (Imágenes 1 y 2).

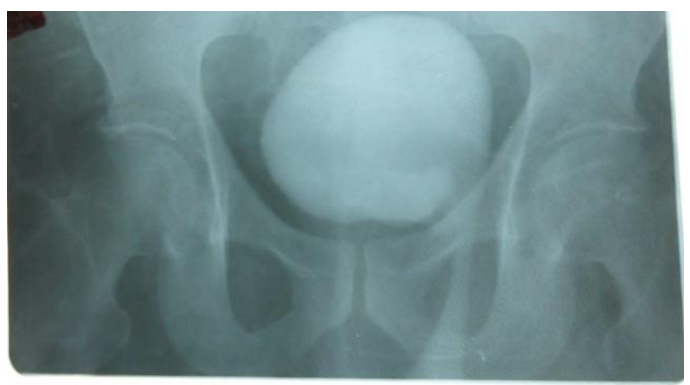

Imagen 1. Cistografía retrógrada. Se observa el paso de medio de contraste a través del defecto de pared, con contenido vesical. Placa de llenado donde se observa el cuello del defecto herniario, donde permite el paso de medio de contraste hacia la porción es $\neg$ crotal, con paredes regulares y su tamaño aproximado de $30 \%$ del volumen vesical

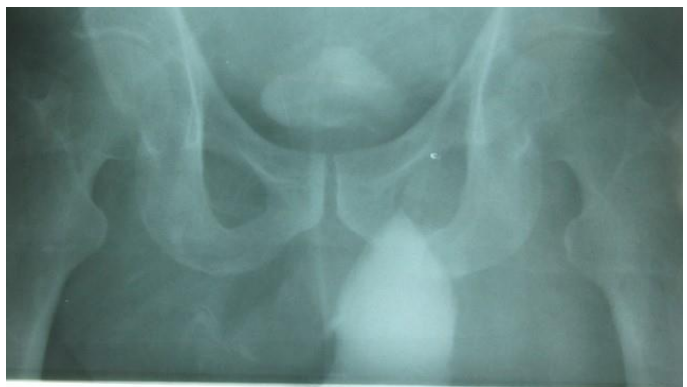

Imagen 2. Cistografía retrógrada, en la que se observa el paso de medio de contraste a través del defecto de pared, con contenido vesical.

En la placa miccional, no se evidenció la presencia de áreas estenóticas a nivel uretral. En una proyección postmiccional se observó orina residual. (Imagen 3). Al alta de UCI, se derivó al Servicio de Urología donde se le dio continuidad a su estudio para posterior tratamiento.

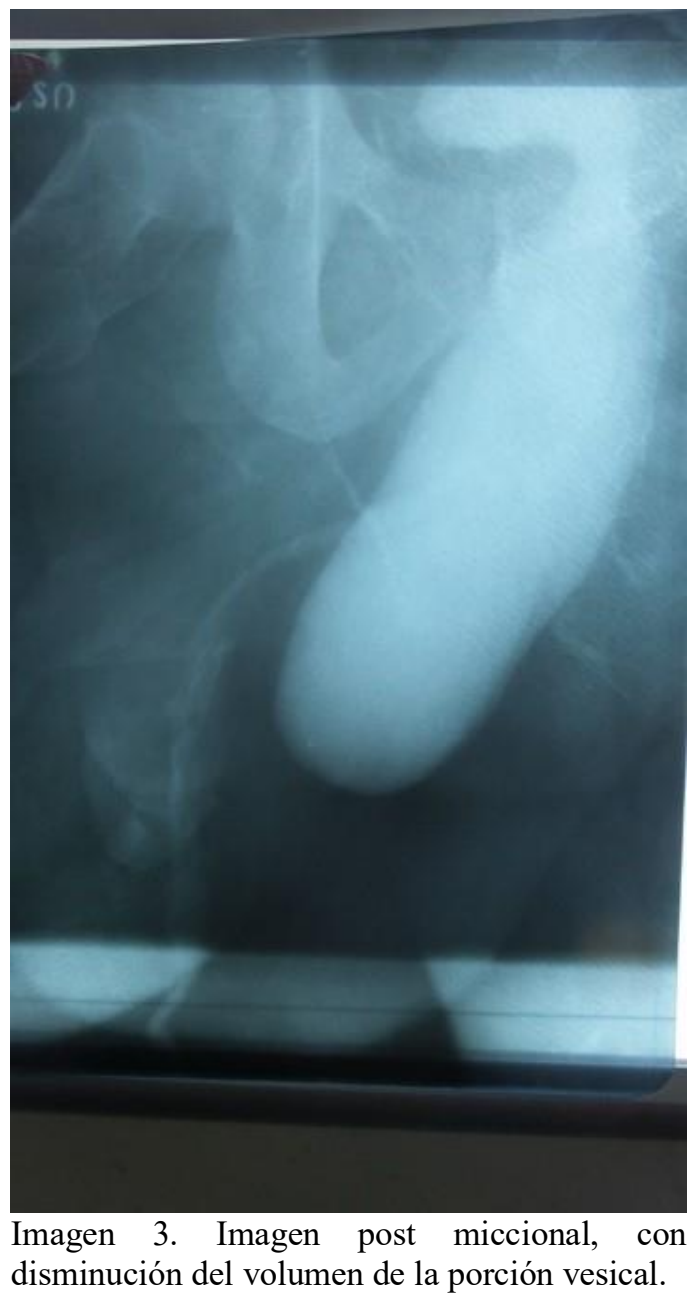




\section{Discusión}

No más de 200 hernias vesicales hay reportadas en la literatura de habla inglesa. (2) Recientemente una revisión sistemática centrada en la búsqueda en los últimos 10 años sobre el tema solo encontró 64 pacientes con esta entidad. La mayoría de estos estudios fueron reportes de casos y pequeños estudios retrospectivos. Lo que afirma la existencia de escasas publicaciones sobre el tema.

A pesar de ser una entidad rara $[0,3-3$ $\%$ de las hernias inguinales en los adultos (3)], su incidencia aumenta en un $10 \%$ en hombres mayores de 50 años. $(2,3)$

La mayoría de los estudios no proveen suficiente información concluyente acerca de los factores de riesgo de este padecimiento, solo se ha notificado el "sobrepeso en hombres" (10,9 \%) según Branchu B y colaboradores. (7)

En la patogenia de la hernia vesical se encuentran implicados, además de los factores propios de una hernia inguinal, la debilidad de la pared vesical con obstrucción en el flujo urinario bajo, que origina un aumento de la presión intravesical, por lo cual su asociación con la hipertrofia prostática es muy frecuente. (3)

Esta patología es asintomática inicialmente en la mayoría de los casos. Cuando presenta sintomatología en ocasiones se encuentran manifestaciones urinarias con polaquiuria, dolor suprapúbico al final de la micción o hematuria. (5) Síntomas adicionales incluyen dificultad para la micción, síntomas irritativos del tracto urinario inferior, vaciamiento incompleto de la vejiga e infecciones del tracto urinario. (4) Se han descrito raros casos de retención urinaria. (5)
La ecografía, la cistografía y la tomografia axial computarizada (TAC) enfocada al sistema genitourinario (uroTAC o cisto-TAC) son pruebas útiles para el diagnóstico. La TAC permite por lo general sospechar el diagnóstico, que se puede confirmar mediante cistografía simple o cisto-TAC. No obstante, estas pruebas se realizan poco en la práctica corriente, debido a la ausencia de interés clínico dado que la presencia de un segmento vesical no modifica la indicación terapéutica ni la técnica quirúrgica. (5) En el caso que se presenta, la alta sospecha clínica y el seguimiento ultrasonográfico $\mathrm{y}$ radiográfico determinaron el diagnóstico.

El tratamiento quirúrgico es el de elección en este tipo de hernias. La disección debe de ser muy cuidadosa para evitar el daño ureteral o la apertura accidental de la vejiga. La cistectomía parcial está indicada en hernias estranguladas con necrosis vesical, asociación de un tumor y en cuellos herniarios menores de $0,5 \mathrm{~cm}$ con imposibilidad de reducción de la vejiga. (8)

\section{Responsabilidades éticas}

Protección de personas y animales. Los autores declaran que para esta investigación no se han realizado experimentos en seres humanos ni en animales.

Confidencialidad de los datos. Los autores declaran que han seguido los protocolos de su centro de trabajo sobre la publicación de datos de pacientes.

\section{Derecho a la privacidad y consentimiento informado. Los autores han obtenido el consentimiento informado de los pacientes y/o sujetos referidos en el artículo. Este documento obra en poder del autor de correspondencia.}




\section{Referencias bibliográficas}

1. Buján Lloret C, García Gómez FJ, de la Riva Pérez PA, Calvo Morón MC, Castro Montaño J. Diagnóstico incidental de hernia vesical mediante PET/TC con ${ }^{18}$ F-FDG. Rev Esp Med Nucl Imagen Mol. [internet] 2019. [consultado 23 enero 2020];38(1):54 disponible

en: https://doi.org/10.1016/j.remn.2018 .02 .003

2. González Urquijo M, Mayagoitia González JC, Rodarte Shade M, Bermea Mendoza JH, Gil Galindo G. Large inguinal bladder hernias: can a preoperative diagnosis be made? Springer-Verlag France SAS, part of Springer Nature [internet] 2019. [consultado 23 enero 2020] Disponible en: https://doi.org/10.1007/s10029019-01955-3

3. Ríos Hernández N. Signo de Mery en paciente con paciente con hernia vesical-inguinoescrotal. Presentación de caso. Anales de Radiología Mexico[internet] 2018. [consultado 24 enero 2020];17. Disponible en: https://doi.org/10.24875/ARM.M18 000009

4. Kandemirli SG, Dikici AS, Nurili F, Tutar O, Mujgan YO, Mihmanli I et al. Bladdercancer in an inguinal vesical hernia. Journalof Medical Ultrasonics[internet] 2018. [consultado 25 enero 2020];45:535-537. Disponible en: https://doi.org/10.1007/s10396017-0854-X

5. Anract J, Charbit D, Rouscoff Y, Peyromaure M. Divertículos y hernias de la vejiga. EMC - Urología. [internet] septiembre 2017. [consultado 24 enero 2020]; Volume $49 \quad \mathrm{n} \circ 3$. Disponible en: http://dx.doi.org/10.1016/S17613310(17)86052-7

6. Martín Marcuartu JJ, López Rodríguez E, Álvarez Pérez RA, Jiménez Hoyuela JM. Hallazgo incidental de hernia vesical en estudio gammagráfico de extensión ósea. Cir Esp. [internet] 2018. [consultado 24 enero 2020] Disponible en: https://doi.org/10.1016/j.ciresp.201 $\underline{8.08 .009}$

7. Branchu B, Renard Y, Larre S, Leon P. Diagnosis and treatment of inguinal hernia of the bladder: a systematic review of the past 10 years. Turk $\mathrm{J}$ Urol[internet] 2018 [consultado 25 enero 2020];44(5): 384-8. Disponible en:https://turkishjournalofurology.com/ en/diagnosis-and-treatment-ofinguinal-hernia-of-the-bladder-asystematic-review-of-the-past-10years-169948

8. Merino Peñacoba LM, Ortiz de Solórzano Aurusa J, Juárez Martín ME, González Perea JG, Beltrán de Heredia Rentería J. Hernia vesical masiva y signo de Mery. A propósito de un caso. revhispanoam hernia. [internet] 2015 [consultado 25 enero 2020];3(2):71-74 Disponible en: http://dx.doi.org/10.1016/j.rehah.2015. 02.004

Correspondencia al autor

Ariel Sosa Remón

asosa@infomed.sld.cu

Doctor en Medicina. Especialista de ler grado en Medicina Intensiva y Emergencias.

Profesor Asistente. Aspirante a Investigador. Unidad de Cuidados Intensivos.

Hospital clínico-quirúrgico "Celia Sánchez Manduley.. Manzanillo, Granma, Cuba.

Aceptado para el blog en mayo de 2020 